\title{
Design and Performance Evaluation of a Dual-Axis Solar Tracking System for Rural Applications
}

\author{
Hachimenum Nyebuchi Amadi and Sebastián Gutiérrez
}

\begin{abstract}
Most rural dwellers in developing countries do not have access to adequate and regular supply of energy and most of these estimated two billion people are poor with no sustainable means of livelihood and therefore rely on wood fuel for their cooking and heating needs. And due to lack of energy, including electricity, socio-economic development is either absent or at abysmally low level. To foster rural development and improved living conditions among this populace, there is need for a reliable, low cost and environmentally risk-free source of energy. This work designed, implemented and evaluated the performance of a dual axis solar tracking system (DATS) using light dependent resistor (LDR) sensors, direct current (DC) motors and microcontroller to make it capable of uninterruptible electricity supply for rural applications. Results of the experiment show that the proposed system is more cost-effective and produces $31.4 \%$ more energy than the single axis tracking system (SATS) and $67.9 \%$ more than the fixed PV panel system (FPPS). Owing to the unique design of the proposed tracking system, solar energy can be tracked and stored continuously so that there is adequate electricity for the consuming population at all times. Though tested on a rural community in Abia State, Nigeria, the proposed system can be adapted to rural communities anywhere in the world.
\end{abstract}

Index Terms - Dual axis tracking system; Renewable energy; Rural electrification; Solar energy

\section{INTRODUCTION}

According to Reference [1], worldwide, 1,456 billion people many of which are in rural areas in developing countries do not have access to electricity, of which $83 \%$ live in rural areas. In sub-Saharan Africa, for instance, less than $10 \%$ of the rural population have access to electricity. It is estimated that seven out of eight rural Sub-Saharan Africans do not have access to electricity at all. The issue of poor quality electricity, however, is a global challenge and not limited to developing nations alone [2]. In Nigeria, for instance, access to adequate and reliable electricity supply is a major developmental challenge for both the urban and rural dwellers [3]. It is even worse in the rural areas and communities where only about $10 \%$ of the population have access to electricity $[4,5]$. What this means is that majority of the rural dwellers are cut off from modern forms of development including education, healthcare, agriculture and even economic development such as small and medium size businesses. Reference [6] reported that Nigeria

H. N. Amadi is with the Department of Electrical and Electronic Engineering of Federal University of Technology, Owerri, Nigeria (email: amadihachy@gmail.com)

S. Gutiérrez is with Facultad de Ingeniería, Universidad Panamericana, Aguascalientes, México (email: jsgutierrez@up.edu.mx) currently suffers from stunted economic growth, reduced leisure time as well as heightened criminality and insecurity arising from lack of steady electricity supply to the rural communities. Electricity enhances human comfort in the home by helping to power the lighting fittings, fans, refrigerators, television, etc. Besides being used for lighting and household purposes, electricity also facilitates the mechanization of many farming operations, such as threshing, milking, and hoisting grain for storage. Electricity allows for greater productivity at reduced cost especially in areas where there is shortage of manpower. Significant relationship exists between access to modern energy services and rural development [7, 8]. Making electricity available to the rural populace especially in the developing countries nevertheless poses big challenges requiring lengthy distribution lines which because of the susceptibility to the elements also create maintenance problems across large sections of the grid. This, in addition to the high cost of the distribution and transmission lines, make rural electrification an expensive operation. Since the recent years, photovoltaics have become one of the fastest growing industries worldwide, the photovoltaic (PV) technology having been generally accepted as a better alternative to fossil fuels for the generation of electrical energy. Photovoltaic (PV) panel converts sunlight into electricity [9]. Besides having the capacity to harness energy from a readily available and unlimited source, PV systems are devoid of the environmental risks usually associated with the conventional energy sources. In the fixed panel, the photovoltaic (PV) panel is mounted fixed and facing one direction only. In this position, the panel is not moving along any axis, but is at a constant position and therefore not able to capture irradiance as per the daily and continuous movement of the sun from morning to night. Low conversion efficiency is a major technical challenge with fixed panel PV systems. To increase PV panel efficiency, a solar tracking device is required to follow the sun as it moves across the sky during the day such that the panels are always perpendicular to the solar energy radiated by the sun and so, able to maximize the amount of power absorbed by the PV system. It has been estimated that, a tracking system produces $30 \%-60 \%$ more power output than the fixed panel system [10]. Two methods of tracking solar energy are by use of a single-axis solar tracker or by the deployment of a dual-axis solar tracking system [11]. The dual axis solar tracker follows the movement of the sun across the sky ensuring that the maximum amount of sunlight strikes the panels all throughout the day so that maximum energy is produced.

Experts say that the angle of inclination ranges between $90^{\circ}$ after sunrise and $+90^{\circ}$ before sunset with $0^{\circ}$ at noon. 
What this means is that the collected solar radiation is $0 \%$ at sunrise and sunset respectively whereas it is $100 \%$ at noon. In other words, due to the variation of solar radiations collection, the PV panels lose at least $40 \%$ of every collected energy. The block diagram of a Dual-Axis Tracking System (DATS) is as shown in Figure 1.

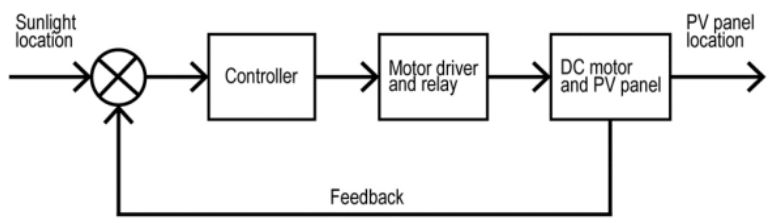

Figure 1. Block diagram of a Dual-Axis Tracking System

In order to determine how the solar tracker would move, it is necessary to consider the movement of the sun in the sky throughout the year. The sun path diagram of Figure 2 shows the annual variation of the path of the sun in Aba, a neighboring town lying within the same geographical zone as the community under study. From the diagram, the movement of the sun in the sky throughout the year in Aba can be viewed in terms of three different scenarios. As the sun rises from the East to set to the West, the sun path may move either in the Southern or Northern region, or it may move almost directly overhead.

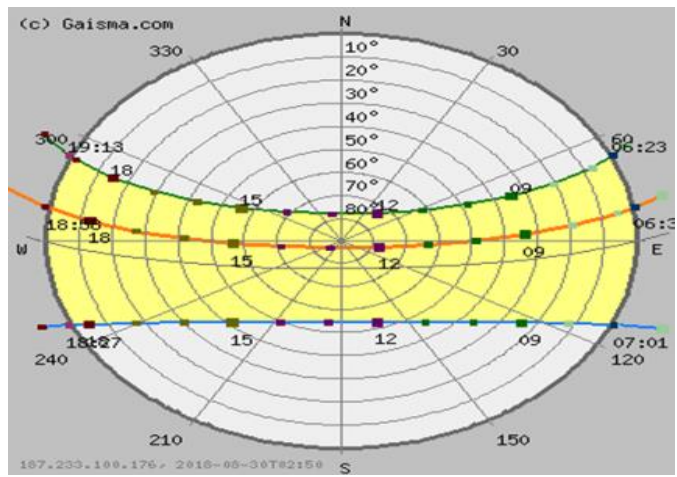

Figure 2. Sun Path

If the path of the sun is in the Northern region, the structure must be able to track the sun from East to West in anti-clockwise direction. But if the path of the sun is in the Southern region, the system must be able to track the sun from East to West in the clockwise direction. Figure 3 shows a dual axis solar tracker.

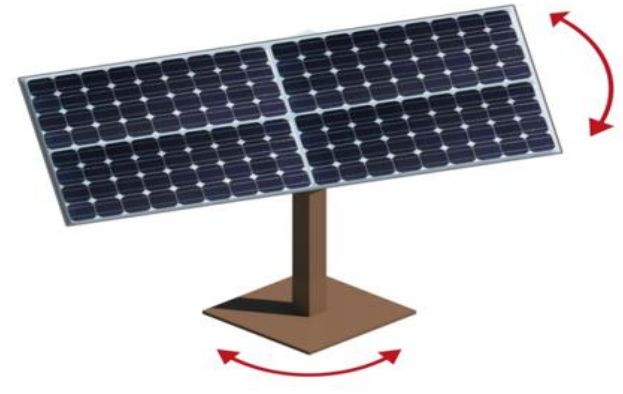

Figure 3. Dual Axis Solar Tracker
If on the other hand, the sun is moving overhead, only the axis which tracks the angular height of the sun will move. However, in all three scenarios, there must be a way to return the tracker to its original position after it has followed the movement of the sun from morning to dusk. For this purpose, limit switches are included in the system so that when the limit switch is triggered at the end of the day, the tracker returns to its original position. As can be seen in Figure 4, the position of the sun with respect to that of the earth changes continuously in a cyclic manner during the calendar year [12].

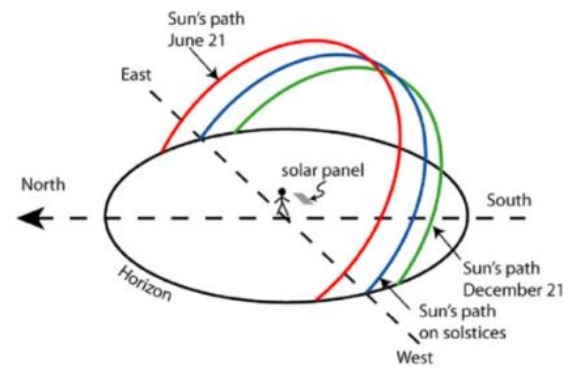

Figure 4. Cyclical movement of the sun with respect to the earth [13]

Solar trackers are categorized into the single axis trackers and the dual axis trackers. Single-axis trackers rotates east to west and follow the sun's movement across a horizontal plane, but dual-axis trackers trace both the vertical and horizontal movements of the sun and can therefore incline or tilt to account for winter and summer sun angles. Because the dual axis solar tracking system has both a horizontal and a vertical axis and can therefore track the sun's apparent motion in the sky, irrespective of where it is positioned on earth, the system has the capacity to maximize the total power output by keeping the solar panels in direct sunlight longer than either the single-axis trackers or fixed PV panels $[14,15]$.

Reference [16] designed a sun tracking system, whereby the movement of a photovoltaic module was controlled to follow the sun's radiation using a Programmable Logic Controller (PLC) unit. Reference [17] deployed a dual axis tracking system by determining through appropriate formulas, the azimuth and solar altitude angles of the sun for a period of one year. The dual axis tracking system which was PLC controlled produced $42.6 \%$ more energy than the single axis tracker and with minimal energy loss in the system. Reference [18] designed and implemented using four LDR sensor and electronic circuits, a sun tracker that comprised a single dual-axis AC motor that traced the sun's movement and used as a stand-alone PV inverter to power the entire system. The total power efficiency of the system was found to be $28.31 \%$. Reference [19] presented a microcontroller-based dual-axis sun tracking system that employed four photo resistors. Results of the study showed that the dual-axis tracking system generated $31.3 \%$ more power. Reference [20] presented a two axis sun tracking system for parabolic trough collector. When compared with a fixed tilted trough, the two axis tracking system was found to produce $46 \%$ more energy. Reference [21] proposed a dual-axis solar tracking controller based on fuzzy logic and using solar records as means of automatically adjusting the 
tilt and azimuth angles, taking into consideration the day of the year and clock time without any need for sensors. Reference [22] designed a two axis tracking system having worm gear drives and four bar-type kinematic linkages to help achieve accuracy in the focusing of the reflectors in a solar concentrator system. Reference [23] designed a simple microprocessor which ensured that the solar collectors in a photovoltaic concentrator pointed towards the sun always hence maximizing the energy harnessed from the sun.

The aim of this paper is to present a dual axis tracking system (DATS) that tracks the sun from east to west and north to south using two pivot points to rotate as well as two LDRs and two motors. In the proposed system, radiations from the sun are captured to the maximum by tracking the movement of the sun in four dissimilar (east, west, north and south) directions.

\section{A. The Study Area}

The study was conducted in Ntalakwu, one of the rural communities in Bende Local Government Area (LGA) of Abia State, Nigeria. Bende LGA is made up of thirteen (13) communities, namely, Bende, Ozuitem, Uzuakoli, Item, Itumbauzo, and Ntalakwu. Others are Umuimenyi, UmuhuEzechi, Igbere, Ugwueke, Ezukwu, Nkpa and Alayi. Bende is situated at $5.56^{\circ}$ North latitude, $7.64^{\circ}$ East longitude and 140 meters elevation above the sea level. Recent studies show that majority of the poor live and work in rural areas of the world [24-26], such as the Ntalakwu community. Agreeably, rural dwellers worldwide need regular access to electricity in order to improve their standard of living, hence the choice of the study area. Figure 5 is the map of the Local Government Areas of Abia State, Nigeria showing Bende Local Government Area in which situates the Ntalakwu community. The weather data (shown in Table 1) obtained for this study was accessed from the National Aeronautics and Space Administration (NASA) Langley Research Center Atmospheric Science Data Center, Hampton, Virginia, United States.

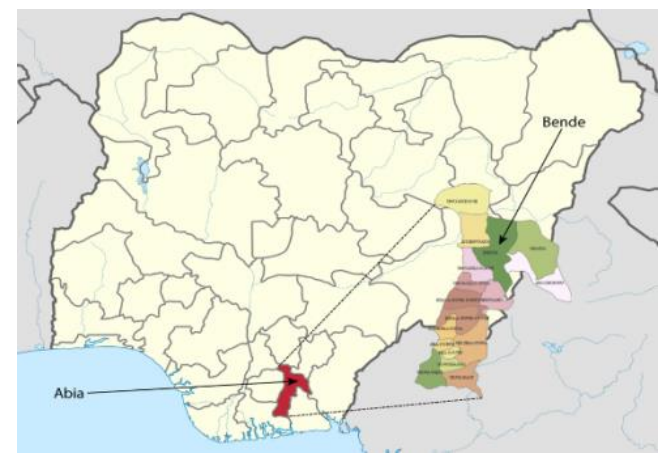

Figure 5. Map of the Local Government Areas of Abia State, Nigeria showing Bende LGA
TABLE 1. ABA, NIGERIA - SOLAR ENERGY AND SURFACE METEOROLOGY

\begin{tabular}{|c|c|c|c|c|c|c|}
\hline Variable & Jan Feb & Mar Apr & : May Jun Jul Aug & Sep Oct & Nov & Dec \\
\hline $\begin{array}{l}\text { Insolation, } \\
\mathrm{KWh} / \mathrm{m}^{2} / \text { day }\end{array}$ & 5.785 .87 & 5.435 .09 & 4.744 .363 .893 .79 & 3.964 .27 & 4.89 & 5.41 \\
\hline Clearness, 0-1 & 0.610 .59 & 0.520 .49 & 0.470 .440 .390 .37 & 0.390 .43 & 0.51 & 0.59 \\
\hline Temperature, ${ }^{\circ} \mathrm{C}$ & 25.425 .9 & 25.825 .8 & 25.724 .824 .023 .9 & 24.224 .4 & 24.7 & 24.7 \\
\hline Wind speed, $\mathrm{m} / \mathrm{s}$ & 2.752 .97 & 2.712 .39 & 2.232 .813 .213 .37 & 72.962 .35 & 52.25 & 52.40 \\
\hline Precipitation, $\mathrm{mm}$ & 27 & 132189 & $\begin{array}{llll}248 & 312 & 365 & 313\end{array}$ & $\begin{array}{lll}3 & 372 & 269\end{array}$ & 993 & 24 \\
\hline
\end{tabular}

Wet days, $\mathrm{d} \quad \quad 2.5 \quad 4.6 \quad 9.1 \quad 12.4 \quad 15.417 .6 \quad 20.420 .721 .7 \quad 16.96 .42 .6$

Source: NASA Langley Research Center Atmospheric Science Data Center [27]

\section{MethodOLOGY}

This study deployed two sets of phototransistor sensors otherwise called light dependent resistors (LDRs), two DC motors and PIC controller. This work preferred the DC Motor with gear arrangements to the Stepper motors because the latter require too much power to provide the stability of tracker positions and therefore decrease the overall efficiency of system. One set of sensors and one motor is used to tilt the tracker in the sun's east - west direction while the other set of sensors and the second motor which is fixed at the bottom of the tracker are meant to tilt the tracker in the sun's north-south direction.

Two light detecting sensors (LDRs) are placed on either side of the panel separated by an opaque plate such that depending on the intensity of the sun rays, when one of the LDRs is shadowed, the other would be illuminated. This makes it possible for the LDR in which the intensity of the sun rays is higher to generate a stronger signal while the other will generate a weaker signal. The difference in the output voltage between the two LDRs thus helps to move the PV panel in the direction in which the intensity of the sun rays is maximum [28]. The study used DC motors instead of AC motors because of its many advantages over the latter. These include its cheapness, easier speed control, position control and operation at low speed which make the proposed tracking system more cost effective and less complex in design. Because DC motors have easier speed control over AC motors, the efficiency of the proposed tracker can be increased when compared with that of the fixed PV panel system (FPPS). Figure 6 shows an inverter and Battery Assembly while Figure 7 shows the proposed Solar Panel Array.

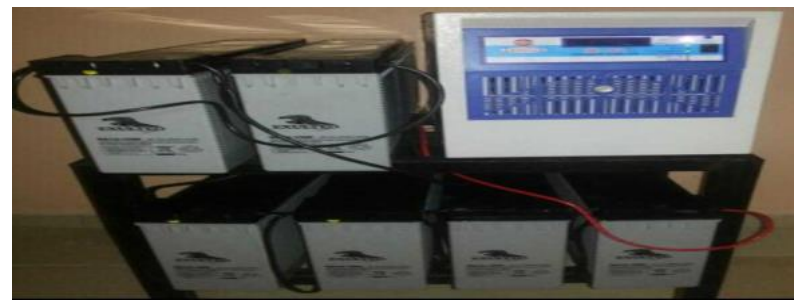

Figure 6. Inverter and Battery Assembly.

The power output (in Watts) is a measure of the rate of 
energy performance of the system. Data collected while carrying out the experiment were measured voltage in Volts (V) and current in Amperes (A). Power output (in Watts) is a function of the measured voltage and the measured current. Figure 8 shows the flow chart of the proposed system.

\section{B. The power conversion efficiency $(\mathrm{PCE})$}

The efficiency of the dual-axis tracking system over that of the single-axis system, the power conversion efficiency (PCE) is calculated as follows:

$\operatorname{PCE}(\%)=[($ Power obtained by dual-axis tracking system Power obtained by single-axis tracker)/Power obtained by single-axis tracker] $\times 100 \%$

The efficiency of the dual-axis tracking system over that of the fixed panel system, the power conversion efficiency (PCE) is calculated as follows:

PCE $(\%)=[($ Power obtained by dual-axis tracking system Power obtained by fixed panel system)/Power obtained by fixed panel system] x 100\%

\section{The design specifications}

The components used in the design and implementation of the proposed system included:

\section{Solar Panel}

The solar panel consists of an array of semiconductor cell arranged in a specific manner to achieve efficient performance. The Solar panels used in this design are of industrial grade with output voltage between $12 \mathrm{~V}$ and $16.8 \mathrm{~V}$.

\section{Microcontroller (PIC16F877A)}

The microcontroller controls all the operations of the tracking system by making it possible to align the solar panel according to the intensity of sunlight by sending signal to the motor to rotate the solar panel in such a manner that the sensors can sense maximum sun rays.

\section{DC Gear Motor (12V)}

DC Motors use lesser power than AC Motors to provide the stability of tracker positions thereby increasing the overall efficiency of system.

\section{Power Relays (10A, 12V)}

Relays were used to control the dc motors by use of low power signal. Relays controlled the DC motors to rotate either in clockwise or anticlockwise direction.

\section{Light Dependent Resistor (LDR)}

A photo resistor or light dependent resistor (LDR) or photocell is a resistor which works on the principle of photoconductivity - the resistance decreases with increasing incident light intensity.

\section{Storage Battery (Lead Acid Type, 24V DC)}

A Battery consists of electromechanical cells which store chemical energy and make it available in an electrical form.
The proposed design has lead-acid type battery. DC Output Voltage $=24 \mathrm{~V}$. Maximum charging current $=1.25 \mathrm{~A}$. Operating temperature $=4^{\circ} \mathrm{F}$ to $140^{\circ} \mathrm{F}$.

\section{Inverter (2KVA 24V)}

Inverter is the heart of every photovoltaic (PV) system because it converts DC power from the PV module and battery bank to AC power in the system. The proposed system employs a $2 \mathrm{KVA}, 24 \mathrm{~V}$ Inverter unit.

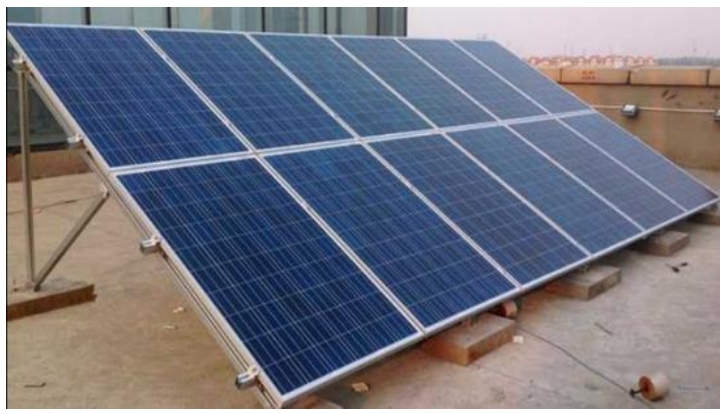

Figure 7. Proposed Solar Panel Array.

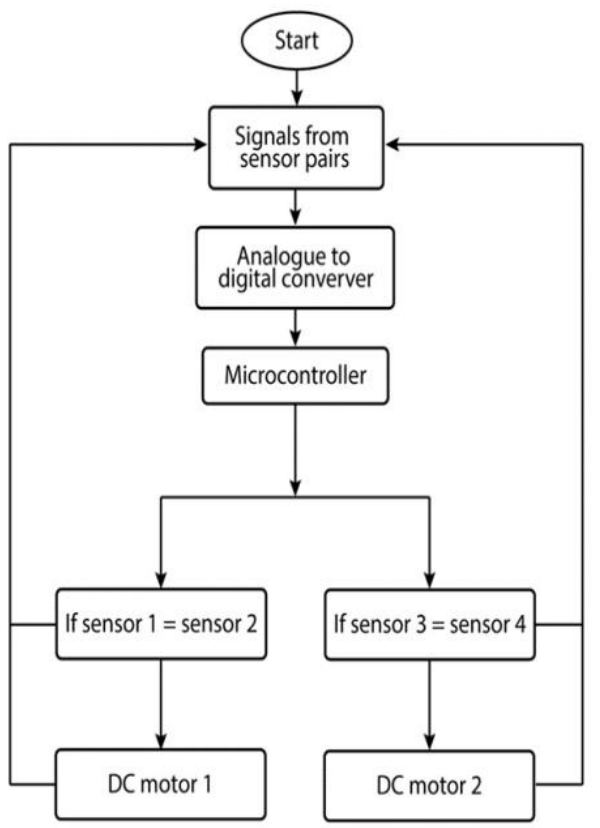

Figure 8 . The system flow chart

\section{RESULTS AND DISCUSSION}

In order to evaluate the performance of the tracking system, experiments were performed to ascertain the energy conversion efficiency of the proposed dual axis against the efficiencies of the single axis and the fixed panel systems. Values of voltage and current from the respective systems were measured hourly from 8:00 AM to 7:00 PM for a single day i.e. 30th December, 2017 with the help of two paid research assistants. These data were later analyzed using the Excel Software to determine the variations of power output for the three systems. Results from the Excel Software are as tabulated on Table 2 while the graphical representation of the power output against day time for each of the system is shown in Figure 9.

From the Table 2, it is seen that the power output for each of the systems initially increased from the morning to 
the afternoon reached peak power at 1:00 PM and thereafter began to decrease hence the general bell shape of the power curves in Figure 9. It can be seen that maximum values of power output were obtained on each system between 12:00 PM and 2:00 PM. It is seen also that the power curves were not completely smooth due to some fluctuations in the values of the output power. This is attributable to cloudy sky and some abnormal atmospheric conditions.

TABLE 2. VARIATIONS OF OUTPUT POWER FOR THE SINGLE AXIS TRACKER, THE DUAL AXIS TRACKER AND THE FIXED PANEL SYSTEMS

\begin{tabular}{lccc}
\hline \hline Time & $\begin{array}{c}\text { Fixed-Panel } \\
\text { (Power in Watts) }\end{array}$ & $\begin{array}{c}\text { Single-Axis } \\
\text { (Power in Watts) }\end{array}$ & $\begin{array}{c}\text { Dual-Axis } \\
\text { (Power in Watts) }\end{array}$ \\
\hline 8:00 AM & 0.12 & 0.33 & 0.39 \\
9:00 AM & 1.98 & 3.84 & 11.42 \\
10:00 AM & 12.63 & 16.03 & 20.14 \\
11:00 AM & 15.69 & 18.31 & 21.14 \\
12:00 PM & 15.45 & 17.94 & 21.77 \\
1:00 PM & 16.14 & 18.82 & 23.12 \\
2:00 PM & 14.37 & 18.61 & 22.09 \\
3:00 PM & 14.47 & 17.67 & 21.28 \\
4:00 PM & 10.21 & 14.18 & 18.20 \\
5:00 PM & 3.10 & 8.93 & 14.16 \\
6:00 PM & 1.68 & 2.16 & 6.02 \\
7:00 PM & 0.04 & 0.04 & 0.09 \\
Total Power & 105.88 & 136.86 & 179.82 \\
(Watts) & & & \\
\hline \hline
\end{tabular}

The calculated power conversion efficiencies (PCE) show that the Dual Axis Tracking System (DATS) produces $31.4 \%$ more energy than the Single Axis Tracking System (SATS) and $67.9 \%$ more than the Fixed PV panel system (FPPS).

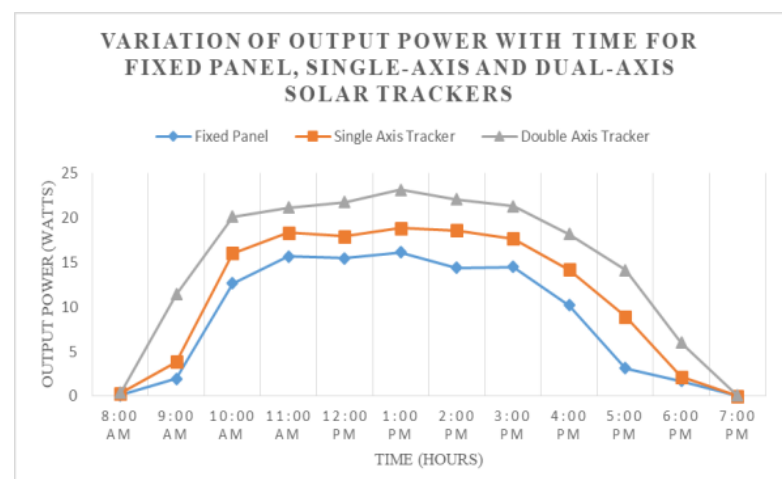

Figure 9. Graphical representation of Output Power over the same time period for the Fixed Panel, the Single-Axis Tracker, and the Dual-Axis Tracking System

\section{CONCLUSION}

This study designed and implemented dual axis solar tracker and later compared the performance with a prefabricated single axis tracker and a fixed PV panel system. Though more complex in design than either the single axis tracker or the fixed panel system, the dual axis tracking system, has the unique advantage of being more efficient in terms of output power and generated total energy as well as being generally more affordable as its cost is only about Five Hundred, Nine Thousand Naira (N509,000.00) only. See the Appendix for Cost Breakdown and Reference [29] for the prevailing prices of Dual-Axis Solar Tracking
Systems. From the results of the experiment, the proposed system has capacity to generate $67.9 \%$ more energy than the fixed panel system and $31.4 \%$ more than the single axis tracker hence confirming the earlier findings by References $[10,14,17]$. Besides, the proposed system can generate more power from each panel and can therefore achieve same power output with fewer panels thus reducing drastically the project's payback time while increasing the overall returnon-investment (ROI). These important advantages of the dual axis solar tracking system over the single axis tracker and the fixed PV panel systems makes it best suited for rural applications.

\section{CONFLICT OF INTEREST}

The authors hereby declare that no conflicting interest exists in the publication of this work.

\section{APPENDIX}

\section{ESTMATED COST OF PROJECT}

\begin{tabular}{lc}
\hline \hline Item Description & Cost in Naira (N) \\
\hline Solar PV Panel & $225,000.00$ \\
Panel Stand/Support & $25,000.00$ \\
DC Motor & $8,000.00$ \\
Storage Battery (Lead Acid Type) & $30,000.00$ \\
Inverter & $94,000.00$ \\
Electrical Circuit (As implemented by the Controller). & $95,000.00$ \\
It includes also the Light Dependent Resistors (LDRs) & \\
which is basically a photocell that works on the & \\
principle of photoconductivity i.e. the resistance value & \\
decreases as the intensity of light increases & \\
Labour Cost (This includes stipend paid out to the two & $32,000.00$ \\
Research Assistants for 16 Hours in a day @ & \\
N500/Hour), & $509,000.00$ \\
Total Cost
\end{tabular}

At the prevailing exchange rate of the United States Dollar to the Nigerian Naira, this is equivalent to (N509,000/N363) $=\$ 1,402.20$

\section{ACKNOWLEDGMENT}

The authors sincerely thank the Authorities of the Bende Local Government Area and the good people of Ntalakwu community both of Abia State, Nigeria for the support and cooperation throughout the project test-run period.

\section{REFERENCES}

[1] International Energy Agency. (2009) "World Energy Outlook 2009", Paris.

[2] Aggreko, S.B. (2015). "The Worldwide Charge Rural Electrification is Crucial Challenge Globally." Available at https://www.elp.com/articles/powergrid international/print/volume20/issue-12/features/the-worldwide-charge-rural-electrification-iscrucial-challenge-globally.html

[3] Hachimenum, N. A. Power Outages in Port Harcourt City: Problems and Solutions. IOSR Journal of Electrical and Electronics Engineering (IOSR-JEEE). Volume 10, Issue 2 Ver. III (Mar - Apr. 2015), PP 59-66 
[4] Diji, C. J. A. (2014). Critical assessment of the Nigerian rural electrification policy. International Journal of Advanced Studies in Engineering and Scientific Inventions. 2(1). Available at http://www.internationalpolicybrief.org

[5] Adaramola, M. S., Oyewola, O. M., \& Paul, S. S. (2012). Technical and economic assessment of hybrid energy systems in South-West Nigeria. Energy Exploration \& Exploitation, 30(4), 533-551.

[6] Amadi, H.N. (2015). Impact of Power Outages on Developing Countries: Evidence from Rural Households in Niger Delta, Nigeria. Journal of Energy Technologies and Policy. 5(3), pp.27-38

[7] Barnes, D and Floor, W. (1996). "Rural Energy in Developing Countries: A Challenge for Economic Development”. Annual Review of Energy and Environment, No. 21

[8] Chaurey, A; Ranganathana, M and Mohanty, P (2004). "Electricity access for geographically disadvantaged rural communities Technology and Policy Insights". Energy Policy, No. 32

[9] Ozcelik, S., Prakash, H., \& Challoo, R. (2011). Two-axis solar tracker analysis and control for maximum power generation. Procedia Computer Science, 6, 457-462.

[10]Priyanka Mane, Akshay Dhumal. (2016). Dual Axis Solar Tracking System Comparative Study And Mechanical Design Implementation, International Journal of Mechanical and Production Engineering (IJMPE), pp. 29-32, Volume 4, Issue 7.

[11]Echendu, R.E. and Amadi, H.N. (2018). Design and Implementation of an Off-Grid Solar Tracker Control System using Proteus Version 8.1. IOSR Journal of Engineering (IOSRJEN). Vol. 08, Issue 4 pp 0412.

[12] Samuel, L.; Ososanya, E.; Latigo, B.O.; Mahmoud, W.; Karanja, G. and W. Oshumare. (2006) Design of a low-cost solar tracking photovoltaic (PV) module and wind turbine combination system, In $21^{\text {st }}$ European Photovoltaic Solar Energy Conference, pp.4-8.

[13] Abood, A. A. (2015). A comprehensive solar angles simulation and calculation using matlab. International Journal of Energy and Environment, 6(4), 367.

[14]Reda, E.T. (2008). Solar Position Algorithm for Solar Radiation Applications. National Renewable Energy Laboratory; NREL/TP-56034302.

[15] Robieux, J. (1980). Future prospects for solar energy. J. Optics (Paris) 11, No. 6; 415-439 $\quad$ http://iopscience.iop.org/0150536X/11/6/010/pdf/0150-536X 116010. dff

[16] Ali, A.M. (2014). Efficiency improvement of photovoltaic panels using a sun-tracking system, Journal of Applied Energy, Vol.79, pp.345-354.

[17] Sungur, C. (2009). Multi-axes sun-tracking system with PLC control for photovoltaic panels in Turkey. Renewable Energy, 34(4), 11191125 .

[18] Wang, J. and LU, C. (2013). Design and Implementation of a Sun Tracker with a Dual-Axis, John's University, Taiwan.

[19] Shyngys, A. S.; Amangeldi, B. B.; Seitzhan, O. and Zhanibek, Z. K (2013). Design and Research of Dual-Axis Solar Tracking System in Condition of Town Almaty, Middle-East Journal of Scientific Research, Volume 17, Issue 12, pp. 1747- 1751.

[20] George, C. (2006). Design and construction of a two axis sun tracking system for PTC efficiency improvement, Renewable Energy. Vol.31, pp.2411-2422.

[21] Armendariz, J., Ortega-Esrtrada, C., Mar-Luna, F., \& Cesaretti, E. (2013). Dual-Axis Solar Tracking Controller Based on Fuzzy-Rules Emulated Networks and Astronomical Yearbook Records. World Congress on Engineering, Volume I.

[22] Agarwal, A. K. (1992). Two axis tracking system for solar concentrators. Renewable Energy, 2(2), 181-182.

[23] Semma, R.P., Imamura, M.S. (1980). Sun tracking controller for multi-kW photovoltaic concentrator system, Proceedings of the 3rd International Photovoltaic Sol Energy Conf, Cannes, France, pp.27-31

[24] World Bank (1999). World Development Indicators. Washington D.C.

[25]FOS (Federal Office and Statistics) (1999). Poverty Assessment

[26]Profile for Nigeria 1980-1996. Federal Office of Statistics. Lagos, Nigeria IFAD (2001). The Rural Poverty Report (2001). International Fund for Agricultural Development, Rome, Italy

[27]NASA Langley Research Center Atmospheric Science Data Center; Hampton, Virginia, United States. Available at https://www.gaisma.com/en/location/aba.html
[28]Deepthi, S.; Ponni, A.; Ranjitha, R and R. Dhanabal. (2013). Comparison of Efficiencies of Single-Axis Tracking System and DualAxis Tracking System with Fixed Mount, Volume 2, Issue 2.

[29] Alibaba Trade Search (2018). Solar Product Prices. Available at https://www.alibaba.com 